\title{
Biographischer Beitrag zu Gustav Heinemann
}

Treffke, Jörg: Gustav Heinemann. Wanderer zwischen den Parteien. Eine politische Biographie, Verlag Ferdinand Schöningh, Paderborn / München / Wien / Zürich 2009, 367 Seiten, $€ 39,90$.

In seiner Bonner Dissertation untersucht Jörg Treffke die parteipolitische Karriere Gustav Heinemanns. Dessen Politik sei von „unverrückbaren Konstanten“ gekennzeichnet gewesen, so Treffke, die sich deutlich in seinem politischen Lebenslauf zeigen würden. Infolgedessen ist das Buch in fünf Großkapitel gegliedert, die den fünf Parteien entsprechen, in denen Heinemann mitwirkte: DDP, CSVP, CDU, GVP und SPD. Eingerahmt werden diese Kapitel zu Anfang von einem Abschnitt zur Jugend- und Militärzeit und am Ende von einem Abschnitt über den Bundespräsidenten Gustav Heinemann sowie einem Kapitel über dessen Politikverständnis. Zwischengeschaltet wird außerdem noch ein Abschnitt über „Heinemann und das ,Dritte Reich' 1933-1945“. Innerhalb der einzelnen Kapitel geht Treffke dann streng chronologisch vor.

Auf breiter Quellenbasis und anhand vieler Zitate zeichnet der Autor Heinemanns politische Anfänge in der Deutschen Demokratischen Partei nach, seinen Wechsel zur Christlich Sozialen Volkspartei, seine Beteiligung an der Gründung der CDU in Essen, den Bruch mit Konrad Adenauer, den Kampf gegen dessen Außen- und Deutschlandpolitik in der Notgemeinschaft für den Frieden Europas und in der Gesamtdeutschen Volkspartei sowie den Eintritt Heinemanns in die SPD und seinen raschen Aufstieg innerhalb der Sozialdemokratie bis in das Amt des Bundespräsidenten. Für die Schilderung dieser besonderen Karriere hat der Autor nicht nur die aktuelle Literatur herangezogen, sondern auch zahlreiche Archive aufgesucht, so das Archiv der sozialen Demokratie der Friedrich-Ebert-Stiftung, wo sich der Nachlass Gustav Heinemanns befindet, das Universitätsarchiv Marburg, das Stadtarchiv Essen und das ThyssenKrupp Konzernarchiv. Darüber hinaus hat er Interviews mit Verwandten und Weggefährten Heinemanns geführt.

Überzeugend schildert Treffke, warum Heinemann in fünf Parteien aktiv war. Dabei wird deutlich, dass dieser ein Mannschaftsspieler war, der von der Notwendigkeit von Parteien zur Durchsetzung politischer Ziele überzeugt war. Allerdings wahrte er immer eine gewisse Distanz ihnen gegenüber und stellte die individuelle Gewissensentscheidung eindeutig über die jeweilige Parteiideologie. Die Unterordnung der eigenen Überzeugung unter eine vorgegebene Parteilinie kam für ihn nicht in Frage. Wenn diese seinen eigenen Anschauungen nicht mehr entsprach, war es für ihn legitim, die Partei zu wechseln.

Gern hätte man dem Autor hier und da etwas mehr Raum gewünscht. Man merkt dem Werk zuweilen an, dass Treffke seine umfangreiche Quellensammlung über Gustav Heinemann häufig nicht ausschöpfen konnte, weil er den Zwängen heutiger Dissertationen unterworfen war. So erfährt der Leser etwa nichts über die Beweggründe und die Ausarbeitung von Heinemanns berühmter Philippika gegen die Politik Adenauers im Bundestag am 23. Januar 1958. Auch über die Reaktion Heinemanns auf seine Nominierung für das Amt des Bundespräsidenten schweigt sich Treffke aus. Interessant wäre es zudem gewesen, etwas mehr über Heinemanns Verhalten beim konstruktiven Misstrauensvotum und der ersten Auflösung des Bundestages durch den Bundespräsidenten 1972 zu erfahren. Was der Autor noch in den Quellen gefunden hat, blitzt aber hier und da durch. So liest man etwa, wie die GVP über die Ost-CDU Geld aus der DDR erhalten hat und dass der CDU-Abgeord- 
nete Ernst Lemmer seinem altem Studienfreund Gustav Heinemann bei der Wahl zum Bundespräsidenten die Stimme gab.

Sicher ist auch Jörg Treffke nicht anzulasten, dass der Verlag das Buch als „die spannende politische Biographie Gustav Heinemanns“ anpreist. Einen solchen Anspruch weist der Autor in der Einleitung eindeutig zurück. Zutreffender ist hingegen der Untertitel „Wanderer zwischen den Parteien“. Treffke zeichnet den Weg Heinemanns durch fünf Parteien in ausführlicher und lesenswerter Form nach. Damit hat er einen wichtigen Beitrag zu dessen Biographie geleistet, an der die künftige Forschung über Heinemann nicht vorbeikommen wird.

Andreas Grau

\title{
Neue Erkenntnisse der Wahlforschung zum Niedergang des katholischen Milieus
}

\author{
Wackers, Frank: Ländlich-katholisch. Gesellschaftliche und politische Veränderungsprozesse, \\ Butzon \& Bercker, Kevelaer 2008, 160 Seiten, € 8,90.
}

Das Emsland, das Münsterland oder das ländliche Bayern gelten in der öffentlichen Wahrnehmung als Hochburgen der CDU/CSU, als Gebiete, in denen aus Tradition „schwarz“ gewählt wird. Frank Wackers stellt dieses Stereotyp auf den Prüfstand. Danach sind solche Regionen gegenwärtig nicht mehr ohne Einschränkungen als Unionshochburgen zu bezeichnen. Vergleichbar der Situation in den sozialdemokratisch dominierten Großstädten habe im ländlich-katholischen Raum, von der Wahl- und Parteienforschung weitgehend unregistriert, das Abschleifen der Hochburgen auch die Unionsparteien erfasst. Wackers macht hier eine Forschungslücke aus, die er mit der vorliegenden Studie in der Tradition soziologischer Erklärungsansätze in Angriff nimmt.

Er eröffnet mit einem knappen Theorieteil, der sich vor allem an der Cleavage- und Milieutheorie der Wahlforschung orientiert. Es folgt ein deskriptiver Teil, der die Veränderungen des Wahlverhaltens in ländlich-katholischen Regionen Bundesland für Bundesland durchmustert und dann die langfristigen Trends vergleichend aufzeigt. Daran schließt sich ein drittes Kapitel an, das verschiedene Erklärungsfaktoren für das beobachtbare Abschleifen dieser Unionshochburgen erörtert. Die Arbeit endet mit einem knappen Ausblick.

Im Zentrum der Untersuchung steht die Entwicklung der Wahlergebnisse in 69 ländlich-katholischen Kreisen zwischen 1949 und 2005. Wackers bestimmt seine Untersuchungsregionen anhand statistischer Schwellenwerte. Als ländlich-katholisch werden auf der Grundlage der letzten verfügbaren Volkszählung von 1987 jene Kreise definiert, auf die drei Merkmale zutreffen: Sie haben einen Katholikenanteil von mehr als 70 Prozent bei einer Einwohnerdichte unter 246 Einwohnern $/ \mathrm{km}^{2}$ und einen Anteil von mehr als 3,2 Prozent in der Landwirtschaft Erwerbstätiger. Im Kartenbild (S. 32 f.) befinden sich diese Kreise mit Ausnahme des thüringischen Eichsfelds alle im Süden und Westen Deutschlands, wobei das Schwergewicht auf Bayern liegt (45 der 69 Kreise).

Wackers wählt einen historischen Weg über die Sozial- und Wahlgeschichte des Katholizismus, um verständlich zu machen, warum die untersuchten Kreise in der Bundesrepublik zu den Hochburgen, das heißt hier zu jenen 15 Prozent der Kreise mit den höchsten Stimmenanteilen der Unionsparteien gehören. Im deskriptiven Teil ist neben der Sichtung der 